\title{
Correction to: Promoting the Sustainable Development Goals in North American Cities
}

David B. Abraham and Seema D. lyer

\section{Correction to:}

D. B. Abraham, S. D. lyer (eds.), Promoting the Sustainable Development Goals in North American Cities, Sustainable Development Goals Series, https://doi. org/10.1007/978-3-030-59173-1

The original version of this book was inadvertently published with the corresponding editor's affiliation being specified as 'Department of Kinesiology' instead of 'Department of BioSciences'. Now, the corrections have been incorporated in Book proof.

The updated online version of the book can be found at https://doi.org/10.1007/978-3-030-59173-1

The updated online version of this chapter can be found at https://doi.org/10.1007/978-3-030-59173-1_1 